\title{
Cambios y permanencias en el mundo del trabajo: un abordaje desde la economía política crítica al caso de la Gran Minería de Oro en Colombia
}

\author{
Walter Mauricio Gallego Medina ${ }^{1}$ \\ https://orcid.org/0000-0002-0697-1276
}

Edvânia Tôrres Aguiar Gomes 1, 3, 4, 5

https://orcid.org/0000-0002-0865-4805

\author{
Aura González Serna² \\ https://orcid.org/0000-0002-3285-863X
}

\footnotetext{
${ }^{1}$ Universidade Federal de Pernambuco, Departamento de Ciências Geográficas, Programa de Pós-Graduação em Desenvolvimento e Meio Ambiente, Recife, PE, Brasil (UFPE)

${ }^{2}$ Universidad Pontificia Bolivariana, Escuela de Ciencias Sociales, Facultad de Trabajo Social, Medellín, Colombia (UPB)

${ }^{3}$ Universidade Federal de Pernambuco, Departamento de Ciências Geográficas, Programa de Pós-Graduação em Geografia, Recife, PE, Brasil (UFPE)

${ }^{4}$ Universidade Federal de Pernambuco, Departamento de Arquitetura e Urbanismo, Programa de Pós-Graduação em Desenvolvimento Urbano, Recife, PE, Brasil (UFPE)

${ }^{5}$ Universidade Federal de Pernambuco, Centro de Biociências, Programa de Mestrado Profissional em Rede Nacional para Ensino das Ciências Ambientais, Recife, PE, Brasil (UFPE)
}

\begin{abstract}
Cambios y permanencias en el mundo del trabajo: un abordaje desde la economía política crítica al caso de la Gran Minería de Oro en Colombia

Resumen: Los desarrollos categoriales e históricos desglosados en este artículo auxilian el análisis de los cambios y permanencias de la explotación de la fuerza de trabajo, haciendo énfasis en el patrón exportador de especialización productiva, a través del cual el negocio de la Gran Minería de Oro en Colombia encuentra nichos de reproducción del capital privado intensificando formas de explotación tanto de la naturaleza como de la mano de obra. El alcance del artículo es contextualizar y comprender la descalificación y profundización de la explotación de la fuerza de trabajo que reproduce, en el siglo XXI, modos de apropiación privada de bienes finitos de naturaleza colectiva. Para tal propósito, se desglosan en perspectiva socio-histórica algunas categorías desde el campo de la economía política crítica propuestas por Marx, tales como: valor de cambio y valor de uso, trabajo necesario y trabajo excedente, plusvalía absoluta y plusvalía relativa, así mismo, se hace una breve caracterización de los patrones de reproducción del capital que han emergido en América Latina entre los años de 1930 y 2016.

Palabras clave: Valor de cambio. Valor de uso. Trabajo excedente. Plusvalía. Gran Minería de Oro.
\end{abstract}

\begin{abstract}
Mudanças e permanências no mundo do trabalho: uma abordagem da economia política crítica ao caso da Grande Mineração de Ouro na Colômbia

Resumo: Os desenvolvimentos categoriais e históricos analisados neste artigo auxiliam na análise das mudanças e permanências da exploração da força de trabalho, enfatizando o padrão exportador de especialização produtiva, através do qual o negócio da Grande Mineração de Ouro na Colômbia encontra nichos de reprodução do capital privado intensificando formas de exploração tanto da natureza como da mão de obra. O objetivo do artigo é contextualizar e compreender a desqualificação e aprofundamento da exploração da força de trabalho que reproduz, no século XXI, modos de apropriação privada de bens finitos de natureza coletiva. Para tal propósito, são analisadas em perspectiva sócio-histórica algumas categorias do campo da economia política crítica propostas por Marx, tais como: valor de troca e valor de uso, trabalho necessário e trabalho excedente, mais-valia absoluta e mais-valia relativa, fazendo uma breve caracterização dos padrões de reprodução do capital que emergiram na América Latina entre os anos de 1930 e 2016.

Palavras-chave: Valor de troca. Valor de uso. Trabalho excedente. Mais-valia. Grande Mineração de Ouro.
\end{abstract}

Changes and permanence in the world of work: a critical political economy approach to the case of the Great Gold Mining in Colombia

Abstract: The category and historical developments analyzed in this article help to analyze the changes and permanence of the exploitation of the gold mining workforce. Emphasis is on the export standard of productive specialization, through which the business 
of the Great Gold Mining in Colombia finds niches of reproduction of the private capital intensifying forms of exploitation of both nature and manpower. The aim of the article is to contextualize and understand the workforce disqualification and deepening exploitation that reproduces, in the 21 st century, private modes of appropriation of finite assets of a collective nature. Some categories of the field of critical political economy proposed by Marx are analyzed in a socio-historical perspective, such as: exchange value and use value, necessary labor and surplus labor, absolute surplus value and relative surplus value, making a brief characterization of the patterns of reproduction of capital that emerged in Latin America between the years of 1930 and 2016.

Keywords: Exchange value. Use value. Surplus labor. Surplus value. Great Gold Mining.

Recibido en 11.10.2017. Aprobado en 08.02.2018. Revisado en 14.03.2018.

cc (7) (8) El(Los) Autor(es). 2018 Acceso Abierto Esta obra está licenciada bajo los términos de la Licencia Creative CC. Commons Atribución-NoComercial 4.0 Internacional (https://creativecommons.org/licenses/by-nc/4.0/deed.es), que permite copiar, distribuir y reproducir en cualquier medio, así como también adaptar, transformar y crear a partir de este material, desde que para fines no comerciales, y que usted fornezca el crédito debido a los autores y a la fuente, insiera un enlace para la Licencia Creative Commons e indique si fueron hechas alteraciones. 


\section{Introducción}

Con el patrón de acumulación flexible que se globaliza en los años de $1970^{1}$, y con el patrón exportador de especialización productiva que surge en América Latina en la década de 1980, el mundo del trabajo enfrentó cambios que involucraron tanto la reorganización del proceso productivo como la emergencia de formas de contratación precarias, temporales y flexibles que implicaron un fuerte golpe para la clase trabajadora al ver crecer el desempleo y disminuir la vinculación laboral formal al estilo del patrón fordistakeynesiano (1930-1970).

Este artículo, es derivado del trabajo final de la Maestría en Estudios Políticos Latinoamericanos, de la Universidad Nacional de Colombia, Bogotá, la cual, se desarrolló fundamentalmente desde la investigación documental. Para la recuperación del componente empírico sobre la metamorfosis del trabajo en la gran minería de oro se analizaron varias fuentes, entre ellas la Agencia virtual de Información de la Escuela Nacional Sindical (ENS), informes del Centro de Investigación y Educación Popular (CINEP) y prensa electrónica alternativa: Silla Vacía, Rebelión y Palabras al Margen. Con el fin de reconstruir datos, profundizar y llenar vacíos en temas que resultaron de la revisión empírica, se implementó la estrategia de entrevistas semiestructuradas a expertos en el tema.

En el primer acápite del artículo, se aborda la descripción de los patrones de reproducción del capital que han emergido en América Latina desde inicios del siglo XX; y en un segundo momento desarrolla algunas categorías de la economía política crítica tales como: valor de cambio; valor de uso; trabajo necesario; trabajo excedente; plusvalía absoluta y plusvalía relativa- y finaliza con un apartado analítico sobre la descalificación que enfrenta el mundo del trabajo en la gran minería de oro en Colombia bajo el patrón exportador de especialización productiva. En síntesis, los tres acápites en cuestión, tienen como propósito contextualizar y comprender la descalificación y profundización de la explotación de la fuerza de trabajo que surge con el capital privado en el sector de la gran minería de oro en Colombia.

Para analizar el trabajo en la gran minería de oro en Colombia, es necesario comprender el desarrollo histórico del capitalismo considerando su manifestación actual a escala regional y mundial. A escala regional, se encuentra el nuevo patrón exportador de especialización productiva ${ }^{2}$ que durante el siglo XXI se viene situando en los países de América Latina y junto con él algunos cambios en la organización del trabajo como las formas de contratación flexible y la marcada división internacional del mismo entre países de centro y periferia; a escala mundial, y como resultado del tránsito hacia el patrón de acumulación flexible en los primeros años de la década de 1970 hasta nuestros días, los proceso de explotación y precarización de la fuerza de trabajo van sufriendo fenómenos de expansión global y generalización en todos los sectores de la economía: industrial, agropecuario, minero, servicios, entre otras.

Para comprender el presente, es importante conocer el pasado y viceversa, en ese sentido, durante los proceso de colonización que iniciaron en el siglo XV, nuestra América se fue configurando como colonia productora de metales preciosos y materias primas, contribuyendo al flujo de mercancías, al desarrollo del capital comercial, al surgimiento de los sistemas bancarios y al desarrollo industrial del continente Europeo.

Posteriormente, el desarrollo neurálgico de la revolución industrial fue forjando con mayor intensidad la relación dependiente de Latinoamérica respecto a los centros capitalistas europeos, es decir, se configuró una división internacional del trabajo, reflejando un sistema mundo de subordinación entre naciones que exportan materias primas hacia otras que las compran para desarrollar la industrialización y la especialización manufacturera.

Esa primera división internacional corresponde a un proceso de mundialización del capital, mientras que en la contemporaneidad nos encontramos con una tendencia a la globalización, la cual:

Surge de la naturaleza del capital desde un comienzo, y significa en realidad: el necesario desarrollo de un sistema de dominación y subordinación internacional [...] con el establecimiento de una jerarquía de Estados más o menos poderosos que disfrutan - o padecen - la posición que se les asigna por la relación de fuerzas prevaleciente - pero que, de tiempo en tiempo, por necesidad se les disputa de manera violenta dentro del escalafón global del capital. (MÉSZÁROS, 2010, p. 58).

Siguiendo la línea del autor, la diferenciación entre naciones permitió por un lado la evolución y diversificación del aparato productivo de los centros económicos de Europa y posteriormente de los Estados Unidos, y por otro lado, la especialización agroexportadora de las periferias del capitalismo generalmente localizadas en las latitudes sur: América del Sur, Asia, y África.

La naturaleza dependiente del capitalismo y el sesgo exportador que se da en los países de América Latina, configuró una estructura productiva que da las espaldas a las necesidades de la mayoría de la población 
trabajadora, deteriorando la consolidación de un mercado nacional. El surgimiento del nuevo patrón exportador de especialización productiva en América Latina acentuado en el sector agro-minero como es el caso de Colombia, representa una tara de la herencia colonial de nuestro subcontinente, revelando procesos de reprimarización de la economía, reducciones del mercado interno, y una profundización en la precarización de la fuerza de trabajo: contratación temporal, tercerización, bajos salarios, prolongación e intensificación de la jornada laboral (OSORIO, 2005).

Según (OSORIO, 2005) en la región se han desarrollado fundamentalmente dos patrones de reproducción del capital: el patrón agro-minero exportador que prevaleció desde mediados del siglo xIx hasta los inicios del siglo Xx, y el nuevo patrón exportador de especialización productiva que puso fin al patrón industrial entre las décadas de 1930 y 1970 y se extiende hasta la actualidad (Tabla 1).

\section{Tabla 1 - Patrones de reproducción en América Latina a partir del siglo xx}

\begin{tabular}{|l|l|}
\hline Patrón de reproducción dominante & Período que cubre \\
\hline Patrón primario-exportador & Hasta la década de 1920 \\
\hline Etapa de transición & Década de 1930 \\
\hline Patrón industrial & $\begin{array}{l}\text { De la década de } 1930 \text { a mediados de la década } \\
\text { de } 1950\end{array}$ \\
\hline Patrón internalizado y autónomo & $\begin{array}{l}\text { De mediados de la década de } 1950 \text { a mediados } \\
\text { de la década de } 1970\end{array}$ \\
\hline Patrón industrial diversificado & $\begin{array}{l}\text { Mediados de la década de } 1970 \text { a la década de } \\
1980\end{array}$ \\
\hline Etapa de transición & Mediados de la década de 1980 a la fecha \\
\hline Patrón exportador de especialización productiva & \\
\hline
\end{tabular}

Fuente: Osorio, 2005.

Es necesario indicar que los cambios de patrones son diferentes en las escalas regional y mundial puesto que la transición hacia el nuevo patrón exportador de especialización productiva en América Latina se combina y coincide temporal y geográficamente con el toyotismo y el patrón de acumulación flexible generalizado en el sistema mundo.

El patrón de acumulación flexible generó cambios a nivel mundial en el interior del mundo del trabajo, sus rasgos más perceptibles fueron la reducción del operario manual, fabril y estable, típico del modelo FordistaKeynesiano. Si bien, la reducción de éste tipo de trabajador se dio a escala global, también hay algunas diferencias regionales en función de las particularidades que asume cada país o región dentro de la inserción y rol en la división internacional del trabajo (ANTUNES, 2000).

Al finalizar la era de la industrialización (1930-1970), y con el surgimiento del nuevo patrón exportador de especialización productiva (1980-hasta la fecha), nuestro subcontinente acentuó su histórico rol de dependencia, este tránsito implicó el abandono de los procesos de industrialización en varios países de América Latina, permaneciendo una franja industrial relevante en algunos casos como Brasil, México y Argentina, pero igualmente subsumida al nuevo proyecto exportador (OSORIO, 2005). Fue evidente entonces que al tiempo que la industrialización declinó, la flexibilización de rasgo mundial debilitó las relaciones formales del trabajo asociadas al patrón industrial o Fordista-Keynesiano y emergieron nuevas formas de organización y contratación del trabajo: relaciones formales e informales, precarizadas, temporales, tercerizadas, etc., que se extendieron a múltiples sectores de la economía: industrial, servicios, manufactura y agro-minero.

Esta breve contextualización es necesaria para analizar los cambios y permanencias en el mundo del trabajo dentro del sector de la gran minería de oro en Colombia, el cual, concentra gran parte de la inversión extranjera directa en el país, pero con baja representación en la generación de empleo. Así mismo, la mano de obra que es incorporada en este sector a través de la tercerización, vivencia procesos de precarización de las condiciones laborales bajo lógicas de intensificación y prolongación de la jornada de trabajo, sumada a la inestabilidad laboral y a la pérdida de derechos laborales que ello conlleva.

Ya hemos planteado algunas transformaciones en el mundo del trabajo, pero las permanencias deben ser evidenciadas, en este sentido, la extracción de plus-trabajo y la subsunción del trabajo al capital, son elemen- 
tos que no se modifican puesto que obedecen al núcleo esencial de la reproducción del capital, revelando que el proceso extractivo de oro no puede prescindir de la fuerza de trabajo, ni mucho menos de su explotación para la generación de plusvalía, como fin último para la acumulación y valorización del capital.

Antunes (2000, p. 219) afirma que "una cosa es que el capital tenga la necesidad imperiosa de reducir el número de trabajadores y la consecuente necesidad de expandir su dimensión constante ${ }^{3}$. Otra muy diferente, es imaginar que eliminando el trabajo vivo el capital pueda continuar reproduciéndose". En otras palabras, el capital siempre busca generar mayores tasas de ganancia y al no poder reducir su inversión en medios de producción y/o materias primas, encuentra la fórmula perfecta de reducir cada vez más el número de trabajadores al tiempo que aumenta sus condiciones de explotación con largas jornadas laborales, intensificación de la fuerza de trabajo, flexibilización de contratos, inestabilidad laboral y reducción de salarios.

En este sentido, antes que hablarse del fin del trabajo lo que se observa es la necesidad del capitalismo en crear y absorber las múltiples formas de trabajo - subempleo, tercerizado, part time, outsorcing, trabajo en casa, trabajo informal, e improductivo, entre otros -, en función de su objetivo de acumulación y expansión sin límite. Por lo tanto, el capital necesita cada vez menos del trabajo estable, pero al mismo tiempo recrea nuevas escalas de asalariados bajo diversas formas de trabajo, los cuales son funcionales a los intereses de valorización del capital.

En la gran minería de oro encontramos que los trabajadores no calificados son incorporados al proceso productivo de extracción del metal, a través de la intermediación de empresas prestadoras de servicios que subsidian la necesidad del capitalista de extraer el máximo de plus-trabajo con una pequeña absorción de fuerza de trabajo sobre la cual, recaen estrategias de intensificación e intensidad de la jornada laboral, además de contar con condiciones precarias de contratación.

Comprender los procesos de precarización a los que viene siendo sometido el mundo del trabajo en la gran minería de oro en Colombia, implica observar las particularidades del sector minero a nivel mundial, tales como: la alta inestabilidad y especulación de los precios internacionales del oro, la competencia intercapitalista por el control del mineral precioso y los costos en los procesos de exploración de suelos. Estos asuntos son determinantes a la hora de contratar fuerza de trabajo en dicho sector, por tal razón, la tercerización laboral con empresas temporales, se convierte en una forma de contratación funcional para la acumulación de capital de las multinacionales mineras al representar formas flexibles en un sector volátil y especulativo pero altamente rentable.

\section{Categorías de la economía política crítica en la Gran Minería de Oro}

Para analizar los cambios y permanencias de la fuerza de trabajo, es necesario comprender con perspectiva histórica la categoría misma de trabajo como una actividad consustancial al ser humano, que involucra un intercambio metabólico entre el hombre y la naturaleza. En esta interacción, los elementos de la naturaleza son transformados en artefactos útiles para satisfacer las necesidades de la auto-reproducción humana, es decir en valores de uso.

Una de las preocupaciones de Marx fue observar cómo el trabajo, además de su potencial creador, se transformó con el surgimiento de la sociedad capitalista en una actividad enajenada, fetichizada, cosificada y opresiva para el mismo hombre, donde el valor de uso orientado a suplir las necesidades humanas quedó subordinado al valor de cambio para satisfacer los intereses de valorización del capital.

No obstante, para que fuera posible la subordinación del valor de uso al valor de cambio, se dio la segmentación entre los trabajadores y los medios de producción. Tal escisión está en el punto de partida del modo de producción capitalista, basada en diferentes modos de violencia como el despojo de la tierra y de los medios de subsistencia de las masas populares, que pasan a ser propiedad masiva de unos pocos. La masa popular despojada de sus medios de producción se convierte ahora en trabajadores libres, quienes no tienen más opción que imitar el ejercicio del despojo o someterse a vender su fuerza de trabajo; la última opción implica la conversión de productores directos en asalariados (SEOANE, 2012).

Desde el núcleo del capital hay una separación diametralmente opuesta entre la producción y el control, (como dice Marx, el capital operó la separación entre trabajadores y medios de producción, entre el caracol y su concha) debido a la alienación que los capitalistas ejercen sobre los productores.

En este proceso de alienación, el capital degrada al sujeto real de la reproducción social - el trabajador -, a la condición de una objetividad cosificada - un mero "factor material de la producción" -, trastocando de ese modo, no solamente en la teoría sino también en la práctica social, la relación sujeto/objeto real. (MÉSZÁROS, 2010, p. 96). 
Es pertinente reiterar que el hombre en las formaciones sociales previas al capitalismo orientaba su acto laborativo para satisfacer sus necesidades humanas - vivienda, alimentación, vestuario etc. -, es decir, los productos eran elaborados para el consumo directo del propio creador - valor de uso -; sin embargo, en la sociedad capitalista los productos elaborados con la fuerza de trabajo toman la forma de mercancías, o sea, su destino no es propiamente el consumo para la satisfacción de las necesidades del propio creador sino el intercambio - valor de cambio - . Con esto, no se quiere insinuar que en las sociedades precedentes no se dieran procesos de apropiación de la riqueza, fruto del trabajo humano, se trata es de hacer énfasis en el sometimiento del trabajo al capital para la valorización y reproducción de éste último.

Se puede decir entonces que en el momento en que se constituye el modo de producción capitalista se generalizan las leyes del mercado en la sociedad y la fuerza de trabajo no escapa de convertirse en mercancía. Con todo lo anterior, el producto del trabajo del hombre adquiere dos dimensiones: valor de uso y valor de cambio. Más adelante se volverá sobre estos dos conceptos. Por el momento, es necesario decir que para los capitalistas el intercambio solo tiene sentido si al finalizar el movimiento de la circulación se adquiere mayor cantidad de dinero que el invertido en el proceso de producción de sus mercancías.

Por lo tanto, la fórmula para representar la circulación capitalista será: $D-M-D+d$ Dónde: $D$ significa el dinero invertido en un primer momento para la compra de capital constante y capital variable; el primero son los medios de producción tales como materias primas y maquinaria, y el segundo es la fuerza de trabajo; $M$ simboliza la mercancía que surge en el segundo momento, es decir, en el proceso de producción; y, $D+d$ es el resultado que se espera del movimiento final - intercambio-venta -, es decir, un dinero incrementado al invertido en la producción de las mercancías. En grandes rasgos, se puede decir que tanto $D$ como $D+d$ tienen que ver con momentos de circulación, mientras $M$, es la fase de producción de mercancías (LAPIDUS; OSTROVITIANOV, 1974).

De acuerdo a lo anterior, el capitalista tiene que comprar diferentes capitales con los cuales, a través de la fuerza de trabajo, creará nuevas mercancías y, posteriormente, vender su nuevo producto; pero al concluir la operación deberá sacar más valor del que ha invertido en el proceso de producción. Este problema solo se puede resolver si se encuentra en el mercado una mercancía que tenga la capacidad de crear valor. Pues, el capital constante - medios de producción, materias primas, herramientas y maquinaria - no puede crear un valor diferente del que contiene, solo transfiere a la nueva mercancía el valor que representa. Se debe precisar que el capital variable - mercancía fuerza de trabajo - es el único que mediante su utilización permite crear un valor superior al que el capitalista paga por su compra representado en el salario.

Encontramos así que "entre las mercancías existentes en la producción capitalista, la más importantes es la fuerza de trabajo [...], porque su utilización permite crear un valor superior al que ella representa con el salario, esto es, permite crear una plusvalía". (SANDRONI, 2005, p. 35). Sin embargo, para que esto último sea real es necesario que el obrero trabaje más allá de cierto tiempo que permita crear un valor superior al pago que recibe por su fuerza de trabajo.

Para comprender un poco más la idea de plusvalía, es preciso pensar en el trabajador independiente y/o libre, quien puede decidir poner un punto final a su trabajo al considerar que ya ha alcanzado lo suficiente para su manutención, es decir, cuando a través de su trabajo siente que ha obtenido lo necesario para la satisfacción de su necesidad - valor de uso -; sin embargo, cuando el trabajador pierde el control de la producción debido al despojo violento de sus medios de producción y es empujado a vender su fuerza de trabajo, la operación es diferente, puesto que el comprador de su fuerza de trabajo - el capitalista - puede obligarlo a trabajar tiempo después de que ya haya creado un valor correspondiente a los medios necesarios para la satisfacción de sus necesidades; en esa medida, el trabajo excedente se convierte en valor excedente que es apropiado por el capitalista, o sea, la plusvalía.

Pero si todo tiene valor ¿cómo se determina el valor de la fuerza de trabajo? Pues bien, como en el capitalismo todo se vuelve mercancía y la fuerza de trabajo no escapa a esta ley, su valor como toda mercancía se calcula por el tiempo de trabajo socialmente necesario para su reproducción y se representa a través de un salario, este último constituye el valor de todos los medios de existencia que permiten revitalizar y recargar la fuerza de trabajo.

Si por algún motivo el salario no cubre:

[...] el mínimo de medios de existencia tanto para el trabajador como para su familia, puede ocurrir no sólo [sic] que el capital se vea privado del flujo de fuerza de trabajo, sino aún más que el obrero no pueda reconstituir la energía gastada en medida suficiente como para continuar trabajando para el capitalista. (LAPIDUS; OSTROVITIANOV, 1974, p. 153).

El dueño del capital contrata al trabajador para utilizar el valor de uso que representa la mercancía: fuerza de trabajo. En caso tal que el obrero no pueda cumplir con sus obligaciones - bien sea por su desgaste 
físico - el capitalista lo reemplazará o despedirá sin vacilar; por tal razón, los señores del capital son fervientes promotores de las concentraciones urbanas, migraciones y desplazamientos de la población para fortalecer lo que Marx calificó como superpoblación relativa o ejército industrial de reserva a la espera de ser contratado, puesto que contar con alta oferta de fuerza de trabajo puede reducir el valor de los salarios.

Como se ha planteado anteriormente, en las sociedades previas al capitalismo el hombre mediante el intercambio con la naturaleza producía directamente los elementos necesarios para satisfacer las necesidades individuales y sociales; sin embargo, con el surgimiento del capitalismo el hombre, para su auto-reproducción, requiere de nuevas mediaciones más allá de la relación con la naturaleza y con los mismos hombres, aparece entonces el salario como mediador para que el creador directo y real pueda acceder al producto de su propio trabajo que ahora le pertenece al capitalista.

Volvamos al trabajo necesario y al trabajo excedente, este último es el apropiado por el capitalista. Según Marx, el tiempo de trabajo necesario es el tiempo durante el cual el obrero reproduce el valor de su fuerza de trabajo representada en un salario, y tiempo de trabajo excedente el tiempo durante el cual crea plusvalía para el capitalista. Esta plusvalía creada por el obrero durante el tiempo de trabajo excedente es el origen de la ganancia capitalista (LAPIDUS; OSTROVITIANOV, 1974). Es importante señalar que:

Los capitalistas, siempre buscarán aumentar la tasa de explotación de los trabajadores. Ya sea por el aumento de la porción de plusvalía a través de la ampliación de la jornada de trabajo o de la intensificación del mismo, o inclusive pagando al trabajador un salario inferior al valor de su fuerza de trabajo es decir a sus medios de subsistencia y reproducción, el objetivo es siempre el mismo: ganar más a costas del trabajador. (SANDRONI, 2005, p. 68).

Hasta aquí ya vimos cómo se determina el valor de la mercancía fuerza de trabajo pero ¿cómo se da el valor de cambio de una mercancía? Pues bien, el valor de cambio de una mercancía cualquiera se expresa por la formula $c+v+m$, esto es, la suma del capital constante ( $c$ ), el capital variable $(v)$ y la plusvalía que en este último crea el trabajador $(m)$. Pero lo que cuenta para la sociedad con relación a la determinación del valor de cambio no es el tiempo de fuerza de trabajo individual gastada para la producción de una mercancía particular, sino el tiempo de trabajo socialmente necesario, es decir la media entre los diferentes productores de una misma mercancía.

En este sentido, dentro de un mismo sector de la economía, se construyen relaciones de competencia, donde cada capitalista buscará fórmulas para reducir el tiempo de trabajo gastado en la producción de sus mercancías, y la empresa que lo logre tendrá mayores tasas de ganancia al vender sus mercancías por el mismo valor de las empresas que no disponen de los métodos de productividad.

No obstante, el propósito de reducir el tiempo de

\section{[...] antes que hablarse del fin}

\section{del trabajo lo que se observa es}

la necesidad del capitalismo en crear y absorber las múltiples formas de trabajo[...] trabajo socialmente necesario y aumentar la producción de mercancías, solo es posible mediante el desarrollo de las fuerzas productivas, es decir, a través de la elevación de la composición orgánica del capital - mayor inversión en capital constante (medios de producción), especialmente en desarrollo técnico científico -, si esto no se da, el mercado no reconocerá el tiempo de trabajo desperdiciado por determinadas empresas y las penalizará con una caída en la tasa de ganancia, mientras que la empresa más avanzada, productiva y tecnificada elevará su lucro. Sin embargo, nuevamente la competencia inter-capitalista obligará a las otras empresas a adoptar el nuevo método de productividad

hasta que este último se generaliza y desaparecen las ventajas obtenidas por el capitalista innovador.

En este punto y con el fin de problematizar más adelante la precarización del trabajo en la gran minería de oro en Colombia es pertinente abordar las dos tipologías de plusvalía: absoluta y relativa. La primera, es el resultado de la explotación sin fin de la clase obrera, a través de la prolongación de la jornada de trabajo y del aumento de la intensidad del trabajo. El caso de la plusvalía relativa es distinto, su método consiste en hacer que el obrero, intensificando la fuerza productiva del trabajo, pueda producir más con el mismo desgaste de trabajo y en el mismo tiempo.

En este sentido, la plusvalía relativa solo es posible mediante la transformación organizativa del trabajo y la incorporación de desarrollo técnico, científico y tecnológico al proceso productivo con el propósito de aumentar el número de mercancías y reducir el tiempo de trabajo socialmente necesario para la producción de las mismas. En palabras de Marx (1946), el aumento de la capacidad productiva del trabajo es cualquier cambio sobrevenido en el proceso de producción, por virtud del cual se reduce el tiempo de trabajo socialmente 
necesario para la producción de una mercancía, gracias al cual una cantidad más pequeña de trabajo adquiere potencia suficiente para producir una cantidad mayor de valores de uso

Es claro que el desarrollo de las fuerzas productivas mediante la incorporación de nueva tecnología absorbe poco capital variable - fuerza de trabajo - en el proceso productivo, sin embargo, la lógica de la productividad no exime la posibilidad de explotar la fuerza de trabajo con fórmulas combinadas de plusvalía absoluta y plusvalía relativa tal y como se observa en la gran minería de oro en Colombia. En palabras de Tavares (2002, p. 126):

El aumento de la plusvalía relativa se da concomitantemente con el aumento de la plusvalía absoluta. En el momento actual, el capital engendra con mucha propiedad la existencia combinada de los dos regímenes de explotación. Las mayores empresas, dotadas de tecnología de punta, se organizan en función de la plusvalía relativa, sin necesariamente abolir la absoluta.

Lo que podemos encontrar entonces es una super-explotación o explotación redoblada de la fuerza de trabajo.

Para precisar, la plusvalía relativa tiene la finalidad de acortar el tiempo de trabajo socialmente necesario en la producción de una determinada cantidad de mercancías, asunto que no se puede confundir con la reducción de la jornada de trabajo. Según Marx (1946, p. 258):

El hecho de que un obrero, al aumentar la fuerza productiva pueda producir en una hora, supongamos, diez veces más mercancías que antes, necesitando por tanto diez veces menos tiempo de trabajo para la fabricación de cada ejemplar de esta mercancía, no es, ni mucho menos, obstáculo para que se le obligue y continúe trabajando largas jornadas de 12 horas.

Sin embargo, lo que sí se puede dar es que gracias a la capacidad productiva, se requiera de menos puestos de trabajo. En esta línea, la gran minería de oro está relacionada con un perfeccionamiento tecnológico que contrasta con el precario desarrollo técnico de la minería tradicional, esta última genera mayor cantidad de empleos que la primera. Entre las grandes firmas del sector minero se da una carrera competitiva por perfeccionar la técnica, es decir, descubrir nuevos caminos por los que se pueda extraer mayor cantidad de oro con altos estándares de productividad, pero con un menor número de trabajadores y con las consecuentes afectaciones al medio ambiente.

La competencia entre multinacionales mineras y la lógica de acumulación constante que subyace al sistema capitalista, ha impulsado la creación de nuevas formas de extracción de los recursos naturales como la explotación a cielo abierto, la fracturación hidráulica - fraking -, entre otros, que revelan un límite absoluto, debido a la escasez y deterioro de los recursos naturales. Ante tal destrucción ambiental y social, el sistema capitalista está revelando sus límites absolutos.

Según Vega Cantor (2012), aunque las grandes empresas mineras necesiten trabajadores ya no requieren vastos contingentes de ellos, ni tampoco generan unas relaciones salariales clásicas. El empleo que generan, es muy escaso y el grado de explotación de los trabajadores es bestial, sin ningún tipo de derechos laborales, e incluso sin contratación directa puesto que predomina el trabajo tercerizado por medio de cooperativas con el objetivo de esconder al patrón.

La relación laboral directa que se establece con el trabajo formal asociado al patrón industrial o FordistaKeynesiano, implica altos costos sociales, que el capitalista interpreta como amenaza para los fines de la acumulación. Pero gracias a la flexibilidad y la desregulación, el capital ha transformado las relaciones formales en relaciones flexibles y precarizadas, tal como ocurre en la gran minería de oro en Colombia, donde los trabajadores no calificados son incorporados al proceso productivo mediante la intermediación de empresas prestadoras de servicios que subsidian la demanda del capitalismo contemporáneo para extraer el máximo de plus-trabajo, utilizando solo un pequeño número de trabajadores.

Aunque el contrato formal y estable asociado al patrón de la industrialización es transformado con el patrón de acumulación flexible, hay elementos centrales que permanecen tales como la subsunción del trabajo al capital, el trabajo enajenado, y precarizado; en tal sentido, el obrero no escapa de la lógica de los bajos salarios, la prolongación de la jornada de trabajo, el aumento de la intensidad o de la intensificación de la capacidad productiva dentro de la empresa. O sea, mudan las formas pero permanecen los contenidos.

De esta manera, se encuentra que en la gran minería de oro se registran procesos de retención de salarios, acompañados del sobre-desgaste físico y mental - sea por la prolongación de la jornada laboral, sea por la intensificación del trabajo, por la misma actividad minera y sus implicaciones en la salud de los trabajadores - que acortan el tiempo de vida útil y de vida total. Según Osorio (2005, p. 12), los trabajos en las multinacionales mineras de oro en Colombia: "constituyen casos en donde el capital se está apropiando 
hoy de años futuros de trabajo y de vida. En definitiva, estamos frente a procesos de super-explotación, en tanto se viola el valor de la fuerza de trabajo".

Con los elementos anteriores, es importante considerar que la idea de remunerar la fuerza de trabajo no puede ser reducida a un asunto puramente salarial, pues se deben tener en cuenta variables culturales, ambientales y las mismas condiciones de desgaste al que se enfrentan los trabajadores no calificados en la extracción de oro, pues a pesar del pago de horas extras o de incrementos salariales por la cantidad de oro producida, la reducción de la vida útil y el tiempo de libertad en la vida total del trabajador no es compensado con el salario extra, que solo remedia una parte de los años futuros que el capital se apropia con jornadas extenuantes o redobladas.

El proceso de precarización del trabajo mediante contratos temporales no es condición exclusiva de las multinacionales mineras de oro que operan en Colombia. En Perú, por ejemplo, se dan los mismos procesos, como en el caso de los trabajadores de Minera Yanacocha en Cajamarca, los cuales se enfrentan a situaciones de inestabilidad laboral y gran desgaste físico en las minas de operación, donde los obreros trabajan doce horas diarias y donde la onza de oro tiene el costo de producción más barato del mundo (SALAS, 2006).

No podríamos analizar el mundo laboral sin las mediaciones y relaciones jurídicas que la figura Estado administra, pues en el caso colombiano la tercerización a través de empresas temporales regentadas por la Ley 50 de $1990^{4}$ (COLOMBIA, 1991), viabilizó la inestabilidad laboral y posibilitó el desmantelamiento de derechos como la sindicalización, según la Escuela Nacional Sindical (ENS), en 2010, en minas y canteras solo había 16 mil trabajadores sindicalizados, de una población total de 213 mil trabajadores en este sector, organizados en 36 sindicatos, lo que da una tasa de afiliación de apenas 7,5\% (VÁSQUEZ, 2011).

Según Harvey (2014, p. 78), la pérdida de derechos en el mundo del trabajo como

[...] las pensiones de jubilación, la sanidad, la educación gratuita y los servicios adecuados que forman parte de un salario social satisfactorio, se ha convertido bajo el neoliberalismo en una forma descarada de desposesión racionalizada, que ahora se ve reforzada mediante la política de austeridad administrada en nombre del equilibrio fiscal.

Por otro lado, según la Federación de Estudiantes Universitarios (FEUC, 2016), la expropiación de los recursos naturales bajo el eje de la explotación minero-energética, por parte de empresas transnacionales que llegan a nuestro país a succionar nuestro subsuelo, no generan siquiera el 1\% de nuevos empleos.

Según Rodríguez (2012), debido a la reestructuración de la industria, la alta tecnificación y la privatización, la minería ofrece cada vez menos empleo, y hoy en día representa aproximadamente el $1 \%$ de la mano de obra mundial, es decir, unos treinta millones de personas, de los cuales, diez trabajan en las minas de carbón.

Además, la poca mano de obra que se articula en la gran minería de oro tiende a reducirse aún más en momentos de crisis, ya que se recurre al despido masivo de trabajadores como medida de ajuste orientada a elevar la tasa de ganancia.

Un ejemplo de este fenómeno puede observarse en el nordeste de Antioquia-Departamento de Colombia -, donde la empresa contratista Estrategias y Minas, cuya usuaria es la Multinacional Gran Colombia Gold ${ }^{5}$, dejó sin empleo a los más de 500 trabajadores que conformaban su nómina. El despido masivo se da porque Estrategias y Minas se declara en quiebra debido a que la multinacional Gran Colombia Gold, a través de su operadora Zandor Cápital, le suspendió el contrato de explotación a causa de la reducción del $28 \%$ de los precios del oro en el mercado internacional en 2013, la pérdida de precio anual más grande en 32 años, según lo reportó la Escuela Nacional Sindical (ARGUMENTANDO..., 2014). Pero para el Sindicato de Trabajadores Mineros de Segovia y Remedios (SINTRAMISER), ${ }^{6}$ lo que de fondo busca Estrategias y Minas con este despido masivo de trabajadores es destruir al sindicato imponiendo un nuevo nivel de tercerización, apelando para ello a la excusa de la quiebra arriba señalada.

Según la entrevista realizada por los investigadores al abogado Jorge Iván Diez de la Confederación General de Trabajo, desarrollada el día 20 de abril del 2014 en la ciudad de Medellín, este argumenta que:

El mecanismo que utilizan las multinacionales mineras para salir del personal contratado a término indefinido, es justificar la caída del precio del oro, para modificar la modalidad de contratación a través de subcontratación a término fijo; subcontratación por temporales o por cualquier otro forma que permite la Ley 50 de 1990. Pero cuando el precio del oro está alto, las empresas no le dicen al trabajador, venga yo lo vinculo directamente con todas las prestaciones económicas con una convención colectiva, puesto que los capitalistas con la tercerización, vieron la funcionalidad para reproducir y aumentar sus tasas de ganancia [...] las multinacionales en minería de oro y de cualquier otro tipo de mineral están ligadas a procesos de intermediación laboral que precarizan el empleo. Lo que más hace carrera en el sector de la minería de oro y 
en otros minerales, son los contratistas. Hay muchísimos trabajadores vinculados a la minería a través de terceros y desafortunadamente el gobierno nacional a través del Ministerio de Trabajo se ha quedado corto frente a la inspección, vigilancia y control para hacerle seguimiento a ese tipo de intermediación y tercerización laboral. Pero no solo el control referido a la intermediación que se hace a través de empresas prestadoras de servicios, sino a las múltiples formas de absorción de la fuerza de trabajo. Por ejemplo en Buriticá-Antioquia, la multinacional Continental $\mathrm{Gol}^{7}$ está adjudicando títulos a terceros [persona natural] por períodos de 1, 2 o 3 años, quienes a su vez terminan subcontratando mano de obra para la explotación minera y le entregan a la multinacional parte de la producción. Lo que se observa es que las multinacionales, cuando no quieren tener un vínculo directo con los trabajadores, recrean muchísimas formas para tercerizar la mano de obra. Aquí se observa una relación que puede catalogarse de pre-capitalista - tipo feudal - pero que es apropiada por el capital y cumple las mismas funciones de apropiación de trabajo, pero sin relaciones salariales.

En este sentido, la experiencia del sindicato SINTRAMISER de la multinacional Gran Colombia Gold es un caso representativo, puesto que inmediatamente después de su creación el 23 de junio de 2013 sufrió un proceso de despido y acoso de los trabajadores sindicalizados; además, la empresa promovió retiros voluntarios, con ofrecimientos de sumas de hasta 20 y 30 millones de pesos colombianos; cantidades que, entre otras cosas, despertaron la suspicacia de los trabajadores, pues no se comprende el discurso de la empresa al decir que está en quiebra. ¿De dónde ha sacado todo ese dinero para los retiros voluntarios? Por lo tanto, los trabajadores asociados al sindicato no descartan que lo del despido sea una estrategia para eliminar el sindicato de una vez por todas (ARGUMENTANDO..., 2014).

\section{Descalificación del mundo del trabajo: ¿fin del trabajo?}

En el sector de la gran minería, la descalificación del trabajo tiene diferentes características. Una de ellas tiene que ver con la reducción de empleo y la inestabilidad; otra característica está relacionada con privilegiar las leyes del mercado internacional como el escenario donde se define el valor de los commodities - oro, carbón, níquel, cobre etc. -, dando un carácter de apéndice al trabajo dentro del proceso productivo, ocultando así su papel como generador del valor.

Otra de las formas de descalificar el trabajo en la gran minería de oro tiene que ver con la elevada inversión en capital constante - relacionada con la tecnología de punta-, donde el desarrollo técnico-científico se vuelve central dentro del proceso productivo y aparece como el principal generador de valor, mientras que la fuerza de trabajo adquiere un carácter secundario; por lo tanto, la clase trabajadora recibe tratamiento de reciclaje y puede ser expulsada o incorporada al proceso de producción según las necesidades de un mercado mundial de minerales que es anárquico, líquido y volátil.

Algunos teóricos que plantean el fin de la sociedad del trabajo, justifican sus tesis con la emergencia y aplicación de la ciencia a los procesos de producción, donde el tiempo de trabajo socialmente necesario pierde centralidad como generador de valor; sin embargo, aunque la sociedad capitalista debilite en gran escala la relación salarial basada en el patrón industrial/fordista-keynesiano, esto no significa que se pueda eliminar el trabajo vivo, ni el trabajo asalariado como único generador de plusvalía.

Si bien los nuevos desarrollos tecnológicos economizan trabajo, no eliminan el trabajo vivo necesariamente. Tales innovaciones posibilitan la sobrevaloración de la máquina, puesto que a través de su uso se cambia la proporción entre el trabajo necesario y el trabajo excedente, sin embargo, la técnica y la ciencia no tienen la autonomía de crear valor de uso y mucho menos de cambio, algo de lo que solo el trabajo vivo es capaz de realizar. En la actualidad es substantivo el mayor protagonismo y poder del trabajo muertoacumulado en medios de producción y materia prima- sobre el trabajo vivo, pero aun así, el desarrollo tecnológico no es argumento suficiente para plantear la desaparición del trabajo vivo y declamar el fin de la clase trabajadora (TAVARES, 2002).

No se trata de decir que la teoría del valor-trabajo de Marx no reconoce el papel creciente de la ciencia, todo lo contrario; la ciencia interactúa cada vez más con el trabajo en la necesidad preponderante de participar del proceso de valorización del capital, pero la ciencia se encontró empequeñecida en su desarrollo por la base material de las relaciones entre capital y trabajo, donde el valor de cambio acabó por imponerse de manera jerárquica a todo los avances científicos y tecnológicos (ANTUNES, 2000).

Según Harvey (2014, p. 114-116),

[...] la contradicción por un lado del trabajo social como el regulador del valor, y el ahorro del trabajo debido a la inversión en innovación tecnológica por el otro, plantea un territorio cada vez más peligroso, al verse 
afectada no solo una creciente proporción de la población sin previsibles oportunidades de empleo, sino también, la reproducción del propio capital, puesto que cuantos más dispositivos de ahorro de trabajo se aplican, más tiende a declinar cuantitativamente el agente que produce valor - el trabajo social -, destruyendo en último término el trabajo socialmente necesario y la producción de valor, y con ellos la base del benefício.

El autor añade que la anterior contradicción tiene algunas consecuencias muy serias, tanto teóricas como políticas, puesto que si en realidad se está extinguiendo el trabajo social y el dinero es una representación del valor del trabajo social con el que se puede hacer el intercambio para acceder a las mercancías, producto del trabajo mismo, entonces no habrá valor qué representar. La representación histórica del valor - la forma dinero - quedará entonces enteramente liberada de su obligación de representar algo más que a sí misma.

En este orden de ideas, Harvey (2014, p. 118) plantea que:

Gran parte de la población mundial se está convirtiendo en desechable e irrelevante desde el punto de vista del capital, lo que aumentará la dependencia de la circulación de formas ficticias de capital y construcciones fetichistas de valor centradas en la forma dinero y en el sistema de crédito, lejos de representar el producto del trabajo social.

Sin embargo, lejos de desaparecer el trabajo social como regulador y generador de valor, se hace hincapié en la vigencia de la teoría del valor-trabajo, pues a pesar de las metamorfosis contemporáneas del trabajo fragmentado, temporal, inestable, improductivo, intelectual, precarizado, part-time, domiciliario, tercerizado, entre otros - el capital ha absorbido el uso general de las metamorfosis señaladas y ha conservado la explotación y subsunción del trabajo al capital; al mismo tiempo, ha profundizado las estrategias de explotación de la fuerza de trabajo al languidecer los salarios en conjunto con las prestaciones sociales, gracias a las nuevas formas de incorporar fuerza de trabajo al proceso productivo.

En este sentido, el presente artículo pone de relieve la importancia y vigencia que tiene para el análisis de la realidad social, el abordaje de la teoría del valor-trabajo y las herramientas de la economía política critica, pues los cambios derivados de la flexibilización tanto en el proceso productivo como al interior de la organización del trabajo y en las nuevas formas de contratación laboral, demuestran que lejos de modificar la contradicción capital-trabajo, ésta se ha profundizado, pues el objetivo siempre será hacer que la producción contenga el máximo posible de trabajo no pago con el menor número de trabajadores que sea necesario.

\section{Consideraciones Finales}

Las metamorfosis del trabajo en el sector de la gran minería de oro demuestran la tendencia del sistema metabólico social del capital en reducir cada vez más el trabajo estable, pero también su necesidad de absorber constantemente las más diversificadas formas de trabajo, manteniendo la lógica de apropiación de plus-trabajo. Estos elementos también confirman la permanencia de las mediaciones de segundo orden, que lejos de modificar el modo de producción capitalista profundizan la necesidad de alienar el trabajo con mayores rasgos de precarización, tal como se observa con el trabajo no calificado en la gran minería de oro en Colombia, especialmente el trabajo tercerizado con empresas prestadoras de servicios temporales.

El desarrollo técnico que se introduce en la gran minería de oro destruye formas de trabajo de la minería tradicional al acaparar tierras de campesinos y comunidades rurales que son concesionadas a las multinacionales, además, las empresas mineras generan poco empleo y obtienen altos estándares de productividad combinados con una gran explotación tanto de los recursos naturales como de la fuerza de trabajo.

La poca mano de obra que se articula en la gran minería de oro tiende a reducirse aún más en momentos de crisis, al recurrir al despido masivo de trabajadores como medida de ajuste orientada a elevar la tasa de ganancia. En momentos de crisis, el objetivo principal del capital es reducir los costos variables de producción e intensificar la explotación de la plusvalía.

La descalificación del trabajo en el sector de la gran minería tiene que ver con la reducción del empleo y la inestabilidad, pero también con el hecho de privilegiar las leyes del mercado internacional como el escenario donde se define el valor de los commodities, dando por un lado el carácter de apéndice al trabajo dentro del proceso productivo, y por el otro lado, valorizando el papel de las innovaciones tecnológicas en la creación de riquezas y en la constitución substantiva del valor de las mercancías. Pero la ciencia no es una fuerza productiva directa, ni crea valor de uso, algo de lo que solo el trabajo vivo es capaz de constituir. 


\section{Referencias}

ANTUNES, R. Os sentidos do trabalho: ensaio sobre a afirmação e a negação do trabalho. São Paulo: Boitempo, 2000.

ARGUMENTANDO caída de precios del oro, empresa minera pretende despedir más de 500 trabajadores. Agencia de Información Laboral de la Escuela Nacional Sindical, Medellín, 27 enero 2014. Disponible en: $<$ http://ail.ens.org.co/noticias/argumentando-caidaprecios-del-oro-empresa-minera-pretende-despedir-mas-500-trabajadores/>. Acceso en: 28 enero 2017.

COLOMBIA. Ley 50 de 1990. Por la cual se introducen reformas al Código Sustantivo del Trabajo y se dictan otras disposiciones. Diario Oficial, Bogotá, D.C., 1 enero 1991. Disponible en: <http://www.alcaldiabogota.gov.co/sisjur/normas/Norma1.jsp?i=281>. Acceso en: 28 enero 2017.

FEDERACIÓN DE ESTUDIANTES UNIVERSITARIOS DE COLOMBIA. El PND de J.M Santos: las 5 locomotoras de la miseria. Representación Estudiantil ante el CSU, 26 abril 2011. Disponible en: $<$ http://repcsu.blogspot.com/2011/04/el-pnd-de-jm-santos-las5-locomotoras.html>. Acceso en: 26 abr. 2016.

HARVEY, D. Diecisiete contradicciones y el fin del capitalismo. Quito: IAEN; Madrid: Traficantes de Sueños, 2014.

LAPIDUS, I. A.; OSTROVITIANOV, K. V. Manual de Economía Política. Madrid: Siglo XXI, 1974.

MARX, C. El Capital: crítica de la economía política. Mexico: Fondo de Cultura Económica, 1946, t.1, v. 1.

MÉSZÁROS, I. Más allá del Capital: hacia una teoría de la transición. La Paz: Vicepresidencia del Estado Plurinacional de Bolivia; [Buenos Aires]: Pasado y Presente XXI, 2010. t. 1.

OSORIO, J. Patrón de reproducción del capital, crisis y mundialización. In: SEMINÁRIO INTERNACIONAL REGGEN, 2005, Rio de Janeiro. Anais electrónicos... Rio de Janeiro: UNESCO, 2005. Disponible en: < http://bibliotecavirtual.clacso.org.ar/ar/libros/reggen/ pp17.pdf $>$. Acceso en: 13 oct. 2016.

RODRÍGUEZ, G. Crecimiento, consumismo, crisis y minería a gran escala. Otramérica, 6 marzo 2012. Disponible en: <http:// otramerica.com/temas/crecimiento-consumismo-crisis-y-mineria-a-gran-escala/1639>. Acceso en: 9 marzo 2016.

SALAS, I. Quilish Hora Cero: Cajamarca, la lucha de un pueblo que defiende su vida y dignidad. Cajamarca, 2006. Disponible en: $<$ http://www.rebelion.org/docs/27178.pdf $>$. Acceso en: 12 sept. 2017.

SANDRONI, P. O que é a mais-valia. São Paulo: Brasilense, 2005.

SEOANE, J. Neoliberalismo y ofensiva extractivista. Actualidad de la acumulación por despojo, desafíos de Nuestra América. Theomai, Buenos Aires, n. 26, 2. sem. de 2012.

TAVARES, M. A. Os fios (in)visíveis da produção: informalidade e precarização do trabalho no capitalismo contemporâneo. 2002. 219 f. Tese (Doutorado em Serviço Social)-Universidade Federal do Rio de Janeiro, Rio de Janeiro, 2002.

VÁSQUEZ, H. La minería en Colombia. Una locomotora sin vagones para el trabajo decente. Agencia de Información Laboral de la Escuela Nacional Sindical, Medellín, 1 agosto 2011. Disponible en: $<$ http://ail.ens.org.co/informe-especial/la-mineria-colombia-unalocomotora-sin-vagones-trabajo-decente/>. Acceso en: 11 agosto 2016.

VEGA CANTOR, R. Capitalismo gangsteril y despojo territorial. Rebelión, 12 feb. 2012. Disponible en: <http://www.rebelion.org/ noticia.php?id=144552>. Acceso en: 12 marzo 2017.

\section{Notas}

1 En la década de 1970 en Colombia, promovido por el gobierno de Misael Pastrana Borrero(1970-1974)tuvo sus orígenes el proceso de financiarización. Mayor poder de grupos financieros, reacomodándose al nuevo patrón de acumulación capitalista del orden mundial. Los principales propósitos fueron los de libertad económica y fortalecimiento del mercado nacional de capitales. El siguiente gobierno, López Michelsen (1974-1978) desglosa estrategias que complementen este liderazgo de hegemonías nacionales hacia la respuesta a las demandas internacionales. Éstas fueron la liberalización del sector comercio exterior; la reforma fiscal que eliminó subsidios y suprimió políticas de fomento y la flexibilización del mercado laboral. Agresivos cambios en la relación capital-trabajo en clara ofensiva contra las organizaciones de trabajadores constituyeron el caldo de cultivo para la implantación del neoliberalismo en el país. La década de 1980 ya expresa los diseños demandados por las políticas de liberalización y desregulación financiera. Esto es, privatizaciones, aumento de capital extranjero en la banca, desmonte del crédito de fomento, manejo de política cambiaria, monetaria y crediticia, el capital financiero decidiendo todas sus garantías para especular y estrangular la economía.

2 El patrón exportador de especialización productiva, se caracteriza por reposar en ejes agrícolas, mineros, industriales o de servicios, sobre los cuales se cuenta con ventajas naturales o comparativas en la producción y comercio internacional. En torno a esos ejes, como producción de petróleo y derivados, soja, ensamble automotriz con grados diversos de complejidad, extracción y procesamiento de cobre y otros minerales, maquila electrónica, call center o industria turística de diverso tipo se articula la nueva reproducción del capital, Propiciando una suerte de especialización en rubros que son privilegiados por inversiones locales o capitales extranjeros, y por adelantos tecnológicos (OSORIO, 2005).

3 Medios de producción tales como materias primas y maquinaria.

4 LaLey 50 de 1990, establece la figura de Empresas de servicios temporales que contrata y ofrece a terceros la prestación de servicios, para que personas naturales colaboren temporalmente con el desarrollo de sus actividades. En tal sentido, la empresa de servicios temporales, actúa como empleador (Art. 71). Asimismo, en elArtículo 77 de la presente Ley, las Empresas de servicios temporales se crean con el fin de atender incrementos en la producción, el transporte, las ventas de productos o mercancías, o los períodos estacionales de cosechas; para el caso de la minería son los períodos de bonanza o 
incremento en la cotización internacional en los valores de los minerales. La Ley 50 de 1990 y el establecimiento de la figura de Empresa de servicios temporales tienen como finalidad flexibilizar el mundo laboral, eliminar derechos históricos de los trabajadores como la sindicalización, disminuir los costos de producción a favor de los empresarios, precarizar las condiciones en el empleo, moderar los costos del despido y permitir la contratación temporal de trabajadores, provocando así inestabilidad en el empleo (COLOMBIA, 1991).

5 Gran Colombia es una compañía canadiense de exploración, desarrollo y producción de oro y plata con enfoque principal en Colombia. Es actualmente el mayor productor de oro y plata subterráneo en Colombia con varias minas subterráneas en operación en sus operaciones de Segovia y Marmato. Gran Colombia actualmente está avanzando en un proyecto para desarrollar una mina de oro y plata moderna a gran escala en sus operaciones en Segovia.

6 Filial de la Confederación General del Trabajo, que aglutina a 340 de los 500 trabajadores despedidos.

7 La canadiense Continental Gold Inc. es una compañía de exploración aurífera en etapa avanzada que tiene el derecho de exploración y desarrollo de cuatro propiedades en Colombia, las que abarcan 168.000ha y entre las que se encuentran Berlín, Dominical y su proyecto emblemático: la mina de oro Buriticá, ubicada en el departamento de Antioquia.

\section{Walter Mauricio Gallego Medina}

waldoneo@hotmail.com

Mágister en Estúdios Políticos Latinoamericanos de la Universidad Nacional de Colombia (UNAL)

Doctorando en medio ambiente y desarrollo de la Universidad Federal de Pernambuco (UFPE)

\section{UFPE}

Av. Prof. Moraes Rego, 1235 - Cidade Universitária

Recife - Pernambuco - Brasil

CEP: $50.670-901$

\section{Aura González Serna}

aura.gonzalez@upb.edu.co

Doctorado en Servicio Social de la Universidad Federal de Pernambuco (UFPE)

Profesora Investigadora de la Escuela de Ciencias Sociales de la Universidad Pontificia Bolivariana (UPB)

\section{UPB}

Circular 1a - 70-01 - Campus Laureles

Medellín-Antioquia-Colombia

Código postal: 050031

\section{Edvânia Tôrres Aguiar Gomes}

edvaniatorresaguiar@hotmail.com

Doctorado en Geografia Humana por la Universidad de São Paulo (USP)

Profesora Titular de la Universidad Federal de Pernambuco (UFPE)

\section{UFPE}

Av. Prof. Moraes Rego, 1235 - Cidade Universitária

Recife - Pernambuco - Brasil

CEP: 50.670-901

\section{Agencia financiadora \\ No se aplica.}

Contribuciones de los autores

Los autores contribuyeron igualmente.

Aprobación por Comisión de Ética y consentimiento para participación
No se aplica.

Consentimiento para publicación

No se aplica.

Conflicto de intereses

No hay conflicto de intereses. 